\title{
The Impact of Interdependence Between External Hires and Incumbents on External Hire Job Performance
}

\author{
Chen Ma ${ }^{1}$, Changjiang $\mathrm{Yu}^{1}$, Junsheng $\mathrm{Zu}^{2}$ \\ ${ }^{1}$ School of Economics and Management, Shangrao Normal University, Shangrao, Jiangxi, China \\ ${ }^{2}$ Antai College of Economics and Management, Shanghai Jiao Tong University, Shanghai, China
}

\begin{abstract}
We aim to enquire into how interdependent relationships, which consist of human capital resource complementarity and similarity, between external hires and incumbents affect external hire job performance. Using an unbalanced panel of 5803 unique lawyers across 16 months from 359 law firms in China, we test the hypotheses in this study. Our empirical results suggest that both human capital resource complementarity and similarity between external hires and incumbents have an inverted $U$-shaped relationship with external hire job performance. These non-monotonic relationships demonstrate that interdependent relationships between external hires and incumbents, reflecting the extent to which their human capital resources are complementary or similar, have both mutualistic and competitive effects on external hire job performance. Theoretical and managerial implications are discussed.
\end{abstract}

Keywords: External hires, Job performance, Human capital resources, Incumbents.

\section{Introduction}

Previous studies have suggested that external hires, compared with internal hires, can bring novel knowledge and skills, and thus can potentially help firms increase their performance and competition, and better adapt to changing environments which can now occur almost anywhere in the world[1]. Not surprisingly, about two-thirds of employments are filled externally nowadays, compared to the case of the 1950s when over 90 percent of employments were filled internally[2]. However, hiring from external markets is a double-edged sword, a powerful vehicle that raises firm creative capability, sustainability, and thus firm performance, but also an immensely controversial process that potentially erodes the outcomes of external hire and threatens firms' instability[3-4].

Considering the important role of external hires in service and product innovation, staying abreast of new environmental changes and keeping competition with competitors, academic and business circles both emphasis the importance of the factors that may affect external hires' job performance[4-6]. In this respect, previous studies have focused either on characteristics of an organization, such as organizational procedures and policies[7], or on endogenous factors of external hires[8-10]. While these studies contributed significantly to our nascent understanding of what factors may affect new hires' job performance, gaps still exist in the existing literature. As mentioned above, previous studies focused on either on characteristics of an organization, such as firm-size, organizational procedures and policies[7], or on endogenous factors of external hires. Beyond these two views, it is possible that interdependent relationships between external hires and incumbents will play a big part in external hires' outcome. The work of Raffiee and Byun (2020) is exceptional[11]. Their study focused on the moderation effect of human capital resources overlap between external hires and incumbents on the relationship between mobility and external hire job performance. But their study doesn't examine the none-linear effect of interdependence between external hires and incumbents on external hire job performance. In contrast, we delineate two different interdependent relationships between external hires and incumbents and examine how these two interdependent relationships non-linearly affect external hires job performance. With firms increasingly dividing their services or productions among many different workers according to their expertise, interdependence between external hires and incumbents is likely to play a big part in external hire job performance.

In this study, an ecological perspective[12-16] is used to explore how interdependence between new hires and incumbents affects job performance of new hires. According to an ecological perspective, two or more individuals are interdependent if the presence of one affects the outcomes of the other[17].

Drawing upon the work of Raffiee and Byun[11], we argue incumbents have both mutualistic and competitive effects on external hires, and we delineate two dimensions of interdependent relationships: human capital resource similarity and human capital resource complementarity. We propose that both human capital resource similarity and complementarity will have an inverted U-shaped relationship with external hire job performance as a result of the joint effects of mutualism and competition.

In the following sections, we present our conceptive framework, develop hypotheses, elaborate our data collection, variable measures, report our empirical results and conclude by discussing theoretical and managerial implications.

\section{Theory and Hypotheses}

\subsection{The Interdependence Between External Hires and} Incumbents

According to ecological theory, organizations are regarded as interdependent when they affect each other's fate[14]. As Barnett and Carroll noted, organizational interdependence can exist at several levels, such as between individuals of 
organizations, between communities of organizations, and between populations of organizations[14]. We focus on interdependence between individuals, in particular interdependence between external hires and incumbents by examining how interdependent relationships between external hires and incumbents affect external hire job performance. In ecological theory, there are two forms of interdependence: competition and mutualism[14]. Competition occurs when one person or group negatively affects other persons or groups. Mutualism occurs when one person or group positively affects other persons or groups [14]. The density dependence model is the most striking example that captures competition and mutualism. The density dependence model suggests that an individual's growth or survival chances can increase with initial increase in the scale of the organization it belongs to. In the density dependence model, mutualism means members of an organization tend to help each other. This is because they make similar demands on the environment and thus, they tend to band together for the same goals. As Aldrich (1999) noted that mutualism occurs because members of an organization making similar demands on the environment combine their efforts, intentionally or otherwise to improve their position, statues or survival chance[12]. However, when the density increases to a certain point, competition becomes dominant as a result of the fact that members compete for the same limited resources. Therefore, U-shaped effect of population density on individual's outcomes like job performance tends to appear due to the combined mutualistic effect when density increases initially and competitive effect when density further increases.

Drawing upon ecological theory and the logic of density dependence model, we propose that interdependence between external hires and incumbents possesses two different forms: mutualism and competition. In this research context (e.g., law firms), mutualism between external hires and incumbents derives from a more complicated or difficult law case that external hires and incumbents have to combine their efforts to do. As a rule, in the practice of law, a lawyer can earn much more from a complicated or difficult law case than an easy one. So, it would be possible for new lawyers and incumbent lawyers to band together (e.g., to combine their complementary or supplementary knowledge of law) to win and implement a complicated law case. Competition between external hires and incumbents derives from the joint need for the same set finite resources[16]. Ruef (2000) carrying capacity is a useful concept to explain when and where competition between external hires and incumbents occurs[18]. Carrying capacity is to be understood as the maximum number of workers having some identity (potential or realized) that can be supported by the environment at a particular point in time[18]. A plausible presumption is that competition is dictated by environmental carrying capacity, and when it is very much larger than required, competition is unlikely to play a big part in new hires job performance. And conversely in the case of environmental carrying capacity which is very close to what is required. In the context of this study, environmental carrying capacity contains the maximum job opportunity that a particular market can provide for a law firm to serve.

In conclusion, there are two forms of interdependence between external hires and incumbents: mutualism and competition. In this study, we focus on two dimensions of interpersonal relationship: human resource complementarity and similarity. It is found that distinct human capital resources, when combined, have the potential to create a greater value than when separated[19]. In this study, we argue that mutualism and competition between external hires and incumbents are dictated by human resource complementarity and similarity. Drawing upon ecological theory, we expect that mutualism between an external hire and incumbents grows with human capital resource similarity and complementarity at a decreasing rate. Meanwhile, competition between an external hire and incumbents grows with human capital resource similarity and complementarity at an increasing rate. Thus, we expect to observe inverted U-shaped relationships between these two dimensions of interdependence and external job performance.

\subsection{Human Capital Resource Complementarity and External Hire Job Performance}

Human capital resources reflect a worker's knowledge, skills, abilities, and others which are important to firms and can be accessed by firms[10]. Human capital resource complementarity captures the extent to which an external hire differs from incumbents in human capital resources[20]. In organizational literature, many scholars have paid great attention to human capital resource complementarity, and a standard postulate in this stream of research is that human capital resource complementarity enables external hires and incumbents to cooperate and combine their distinct knowledges, skills and abilities to create an amount of value which is greater than the sum of individual parts[19]. However, our knowledge of how human capital resource complementarity may affect external hire job performance is still limited. To date, the empirical evidence of the relationship between human capital resource complementarity and external hire job performance is particularly lacking. While Raffiee and Byun (2020) have only examined the monotonic impact of human capital resource complementarity on external hire job performance[11], we argue that human capital resource complementarity will have an inverted U-shaped effect on external hire job performance.

We argue that at low levels of human capital resource complementarity between external hires and incumbents, increases in human capital resource complementarity can produce mutualistic benefits. It is important to note that external hires are especially lacking of firm-specific skills and knowledge[21], thus they can promote their work efficiency when working along with incumbents whose firm-specific skills and knowledge are crucial for increasing work efficiency and decreasing errors. In addition, incumbents can also learn from external hires if human capital resource complementarity between them is at a low level[5], which in turn can propel incumbents to provide, in return, external hires with what is needed for their jobs.

However, as human capital resource complementarity further increases, competition between external hires and incumbents is likely to increase. This is because too much difference in human capital resources will make it hard for external hires and incumbents to learn from each other, which in turn leads to a high level of misunderstanding, communication difficulty 
and hardness to identify each other's. One may argue that it would be possible for external hires to learn much more from incumbents when complementarity is high than when it is low under the premise that they have the ability to learn from each other. But in the modern business world, in order to achieve economic of scale, firms increasingly organize their work according to the workers' distinct expertise, such as dividing products or services design, components manufacturing and final assembly among many different workers. Therefore, as human capital resource complementarity increases to a certain level, further increase in human capital resource complementarity will make it increasingly difficult or even impossible for external hires and incumbents to learn from each other. As Hayes et al. (2006) noted that a certain level of overlap in human capital resources between employees is essential for them to efficiently learn from each other[22]. Thus, it is reasonable to predict that at a high level of human capital resource complementarity, competition between external hires and incumbents increases with human capital resource complementarity at an increasing rate.

In summary, we argue that at low levels of human capital resource complementarity, mutualism between external hires and incumbents increases with human capital resource complementarity at a decreasing rate but that at high level of human capital resource complementarity, competition between external hires and incumbents increases with human capital resource complementarity at an increasing rate. Because job performance is determined by a net value of mutualism and competition, we propose an inverted U-shaped relationship between human capital resource complementarity and external hire job performance.

H1: Human capital resource complementarity will have an inverted U-shaped relationship with external hire job performance.

\subsection{Human Capital Resource Similarity and External Hire Job Performance}

Human capital resource similarity between an external hire and incumbents refers to the extent to which an external hire's human capital resources overlap with the human capital resources embedded within incumbents[20]. About human capital resource similarity, there are two sharply contradictory arguments. The first one, which supports the competition between an external hire and incumbents, argues that the intensity of the competitive pressures exerted by incumbents on an external hire is in direct proportion to human capital resource similarity between them[16]. The other one, which supports the mutualism between an external hire and incumbents, argues that human capital resource similarity is important for them to understand, learn from, cooperate with and positively identify with each other[4,10,23].

In this study, we argue that human capital resource similarity between an external hire and incumbents can produce competitive and mutualistic effect on an external hire's job performance simultaneously. Furthermore, we argue that these two effects grow with the level of human capital resource similarity, but they grow at a different rate. In particular, we argue that the mutualistic effect on external hire job performance grows with human capital resource similarity at a decreasing rate, and meanwhile, the competitive effect on external hire job performance grows with human capital resource similarity at an increasing rate. These arguments are based on the following reasons: When the level of human capital resource similarity between an external hire and incumbents is low, increases in human capital resource similarity increase the chance of interpersonal communication, learning, resource flows and information sharing. These mutualistic effects will help them discover and implement new ideas, which in turn can promote their job performance. But the marginal mutualistic benefit of human capital resource similarity becomes smaller as the level of human capital resource similarity increases, this is because external hires haven't established a stable and trustable relationship with incumbents[1,24].

However, at high levels of human capital resource similarity, as human capital resource similarity further increases, competition between an external hire and incumbents is likely to increase. This is because external hires whose human capital resources are highly similar to the incumbents of his firm are prone to a harsher competition with the incumbents as a result of the fact that they tend to draw upon and compete for a common resource pool (e.g., working opportunities, promotion opportunities, clients)[25-26]. Their combined resource requirements are likely to reach the firms' carrying capacity[18]. Multiple key resources required in common become scarce, leading to reinforced competition between external hires and incumbents[18]. Another potential problem is that when human capital resource similarity between external hires and incumbents is very high, external hires and incumbents are homogeneous. In general, homogeneous can restrict creativity and innovation[17], which in turn further erodes external hires' job performance. Indeed, it is precisely this logic that pursued so many firms to turn down the applications of external hires with high human capital resource similarity[10]. Therefore, at high levels of human capital resource similarity, the competitive effect on external hire job performance grows with human capital resource similarity at an increasing rate. Combined, we expect there is an inverted U-shaped effect of human capital resource similarity on external hire job performance:

H2: Human capital resource similarity will have an inverted U-shaped relationship with external hire job performance.

\section{Methods}

\subsection{Context and Data}

The sample for this study was collected from the law firms in China. The law firms have several attributes which make it a unique and appropriate place for us to empirically test the hypotheses in this study. First, the Chinese law firms are stringently regulated by the governments (in particular the Ministry of Justice of the People's Republic of China, or MJPRC for short) to report their revenue earned, the names of their client, the services provided, the details of the lawyers (for example, whether a lawyer is hired from external markets or not) who provided the services and so on, which provides the information and data for us to accurately measure the variables in this study. Second, reporting requirements enable us to overcome empirical challenges concerning measuring 
human capital similarity and complementarity[27]. Third, the Chinese law firms chiefly draw on their workers' human capital resources to create profits. Fourth, in recent years Chinese society and markets have experienced a relatively fast development. In order to stay abreast of social development and markets change and to serve their clients better, many Chinese law firms are likely to hire externally rather than internally, not only because external hires are characterized and valued by their relatively novel knowledge and skills, but because in Chinese society external hired lawyers are reported to have been more competent, energetic and dedicated than incumbent lawyers.

Our dataset originally contains the data of 6466 unique lawyers from 359 law firms between 2018 and 2020. Since our study focuses on the human capital resource similarity and complementarity between external hires and incumbents, we drop lawyers who appear once during the sample period. This is because according to Cameron et al. (2011) these observations are likely to bias statistical inference if they are calculated in the regression models[28]. Finally, our sample consists of an unbalanced panel of 5803 unique lawyers across 16 months.

\subsection{Measure}

Dependent variable. Job performance is measured in terms of revenue from legal services that a lawyer has provided. Based on the prior studies[29-30], We calculate job performance as the sum of all service contracts a lawyer is involved in within a given period $t+1$. The virtue of this measure is that it can objectively capture a lawyer's job performance.

Independent variables.

Independent variables. There are two independent variables in this study: human capital resource similarity and human capital resource complementarity. According to the suggestion of Bloom etc.[31], we calculate human capital resource similarity and complementarity. First, we create a knowledge-relatedness matrix, in which 56 legal issues are predefined. These 56 legal issues contain insurance payout, trust mortgage, disposition of non-performing asset, matrimonial cause etc. The knowledge-relatedness matrix is employed as a weigh matrix to measure the extent to which the human capital resources of an external hire is similar to or complementary to that of firms. Second, according to the method suggested by Breschi and Malerba[32], we calculate the knowledge-relatedness matrix. The matrix is employed as the angular distance of the issue cooccurrence vectors[32]:

$$
\Omega_{i j}=\frac{\sum_{k=1} R_{i k} R_{j k}}{\sqrt{\sum_{k=1} R_{i k}^{2} \sqrt{\sum_{k=1} R_{j k}^{2}}}}
$$

In the matrix $\Omega_{i j}$, if issue $\mathrm{i}$ appears in a report $k$, then $R_{i k}=1$. Otherwise, $R_{i k}=0$. The knowledge-relatedness matrix $\Omega_{i j}$ reflects essentially complementarity between issues in the sense that the value of $\Omega_{i j}$ reflects the extent to which an external hire and the firms combine their efforts for the issue $i$ and issue $\mathrm{j}$. Third, we employed the method suggested by Jaffe (1986) [33] to measure the extent to which an external hire's human capital resources and firms' human capital resources is similar or complementary.

$$
\Delta_{m n}=\frac{f_{m t} \Omega e_{n t-1}^{\prime}}{\sqrt{f_{m t} \Omega f_{m t-1}^{\prime} \sqrt{e_{n t-1} \Omega e_{n t-1}^{\prime}}}}
$$

where $f_{m t}=\left(f_{m t, t}, f_{m t, 2}, \ldots \ldots, f_{m t, 56}\right)$ indicates firm m's share in each issue out of the firm's total revenue at time $t$, and $e_{n t-1}=\left(e_{n t-1, t}, e_{n t-1,2}, \ldots \ldots, e_{n t-1,56}\right)$ indicates lawyer n's share in each issue out of the law firm' total revenue at time $\mathrm{t}-1$.

Fourth, we calculate human capital resource complementarity between an external hire and firms by replacing diagonal entries of $\Omega_{i j}$ with zeros, and calculate human capital resource similarity by using off-diagonal entries of $\Omega_{i j}$ [11].

Controls. We control for the following variables in order to rule out some external explanation for external hire job performance. First, prior studies have suggested that firm-specific human capital resources can affect employee identity, which in turn may affect job performance[34]. Firm-specific human capital resources can be reflected by tenure. It is likely that an employee with a long tenure has a stronger organizational identity, better working skills, and thus better job performance than one with a short tenure. Therefore, we control for tenure, which is measured as the number of years the lawyer has been with the law firm. Second, compared with a small law firm, a large law firm has some built-in advantages, which can provide more job opportunities for its lawyers. As a result, a lawyer working at a large law firm can have a better job performance than one working at a small law firm. In fact, it is found that employees working at a large firm have a high level of working efficiency and job performance than employees working at a small firm[35]. For this reason, we control for firm-size, which is measured as the number of the lawyers working at the firm. Finally, we control for a set of demographic variables. These variables are education and discipline background. It seems that a lawyer with higher education has a higher working efficiency. The same can also be said for discipline background. It is likely that a lawyer who specialized in criminal law has a better working skills and efficiency in dealing with criminal issues than one who specialized in family dispute. We use dummy variables to measure education and discipline background. Particularly, we use 1 to indicate a lawyer with a college degree and 0 to indicate a lawyer without a college degree. In the same way, we control for discipline background, coded 1 if a legal service a lawyer provides fits in with his discipline background, and coded 0 otherwise.

\subsection{Empirical Strategy}

We test our hypotheses by panel regression models. Since there are some missing observations in our dataset, we employ unbalanced panel regression model, where lawyer fixed effects which control for unobserved time-invariant lawyer characteristics are included in the regressions. We use SAS 9.4 statistic software to estimate our panel regression models. 


\section{Results}

Table 1 represents the regression results of job performance. Model 1 includes controls. Model 2 adds the effect of human capital resource complementarity similarity and their squared term on Model 1. Our hypotheses are examined by Model 2.

Table 1: Regression Results of Job Performance

\begin{tabular}{|c|c|c|}
\hline \multirow{2}{*}{ Variable } & \multicolumn{2}{|c|}{ Job satisfaction } \\
\hline & Model 1 & Model 2 \\
\hline Tenure & $0.03 * * *$ & $0.02 * * *$ \\
\hline Firm-size & $0.02 * * *$ & $0.02 * * *$ \\
\hline Education & $0.03 * * *$ & $0.04 * * *$ \\
\hline Discipline back-ground & -0.00 & -0.00 \\
\hline HCR complementarity & & $0.03 *$ \\
\hline HCR complementarity square & & $-0.05 * *$ \\
\hline HCR similarity & & $0.02 *$ \\
\hline HCR similarity square & & $-0.09 * *$ \\
\hline Constant & $2.50 * * *$ & $3.51 * * *$ \\
\hline Time fixed effects? & $\mathrm{Y}$ & $\mathrm{Y}$ \\
\hline Lawyer fixed effects? & $\mathrm{Y}$ & $\mathrm{Y}$ \\
\hline R-Squared (Within) & 0.271 & 0.31 \\
\hline Change in R-Squared (Within) ${ }^{\mathrm{a}}$ & & $0.09 * * *$ \\
\hline \multicolumn{3}{|c|}{$\begin{array}{l}\text { Note: Change in R-Squared (Within) }{ }^{\mathrm{a}} \text { is compared to Mo } \\
\mathrm{N}=5803 \text {. } \\
\text { Standard errors are clustered by lawyers and law firms. } \\
\text { HCR is Human Capital Resource for short. } \\
{ }^{*} \mathrm{p}<0.05 ;{ }^{* *} \mathrm{p}<0.01 ;{ }^{* * *} \mathrm{p}<0.001 .\end{array}$} \\
\hline
\end{tabular}

Hypothesis 1 predicts that human capital resource complementarity has an inverted U-shaped relationship with external hire job performance. Model 2 provides the empirical results for Hypothesis 1 . Model 2 suggests that the coefficient for human capital resource complementarity is positive and significant $(\beta=0.03, p<0.05)$, and the coefficient for human capital resource complementarity square is negative and significant $(\beta=-0.05, \quad \mathrm{p}<0.01)$. Thus, Hypothesis 1 is supported by our empirical results.

According to the regression results of Model 2, an external hire's expected job performance is 5.830 thousand (in RMB) when human capital resource complementarity is 0 , if all other variables take their mean values. Furthermore, we calculate an external hire's highest expected job performance based on the regression results of Model 2. The result suggests that the highest expected value of job performance is 12.428 thousand (in RMB), which occurs when human capital resource complementarity is 0.714 . However, an external hire's expected job performance drops to 6.504 thousand (in RMB), when human capital resource complementarity is 1 . In other words, all else being equal, an external hire's expected job performance would be 113.17 percent $(=12.428 / 5.830-1)$ greater if human capital resource complementarity between an external hire and incumbents were to change from 0 to 0.714 , and the external hire's expected job performance would likely drop as the human capital resources complementarity further increases. To further investigate the effect of human capital resource complementarity on external hire job performance, we plotted the results in Figure 1. Figure 1 was created by the following method: First, we constrained all other variables in Model 2 (except human capital resource complementarity and its squired term) to their mean values. Second, we took human capital resource complementarity values ranging from four standard deviations below the mean to four standard deviations above the mean (and human capital resource complementarity squared term was calculated accordingly). Finally, we calculated the values of external hire job performance based on Model 2, and plotted Figure 1 using
SAS 9.4. Figure 1 suggests that human capital resource complementarity has an inverted U-shaped relationship with external hire job performance. This result further supports Hypothesis 1 .

Hypothesis 2 predicts that human capital resource similarity has an inverted U-shaped relationship with external hire job performance. The empirical results for hypothesis 2 are listed in model 2 , suggesting that human capital resource similarity is positively related to external hire job performance $(\beta=0.02$, $\mathrm{p}<0.05)$, and that its squared term is negatively related to external hire job performance $(\beta=-0.09, \mathrm{p}<0.01)$. Thus, these results support Hypothesis 2.

In order to have a better understanding of how external hire job performance changes with human capital resource similarity, we calculate the highest expected value of external hire job performance based on Model 2. The result suggests that the highest expected value of external hire job performance is 13.185 thousand (in RMB), which occurs when human capital resource similarity is 0.811 . In addition, based on model 2, we calculated that an external hire's expected job performance is 3.003 thousand (in RMB) when human capital resource similarity is 0 , if all other variables take their mean values. And we calculated that an external hire's expected job performance is 11.351 thousand (in RMB) when human capital resource similarity is 1 , if all other variables take their mean values. These results suggest that all else being equal, an external hire's expected job performance would be 339.06 percent $(=13.185 / 3.003-1)$ greater if human capital resource similarity between an external hire and incumbents were to change from 0 to 0.811 , and the external hire's expected job performance would likely drop as the human capital resources similarity further increases. We plotted Figure 2 the way we plotted Figure 1.

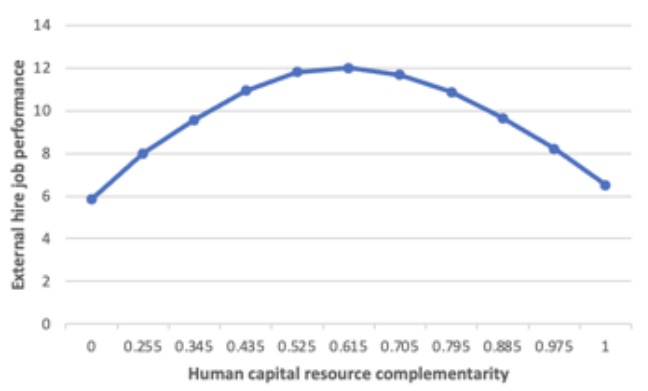

Figure 1: The inverted U-shaped relationship between human capital resource complementarity and external hire performance

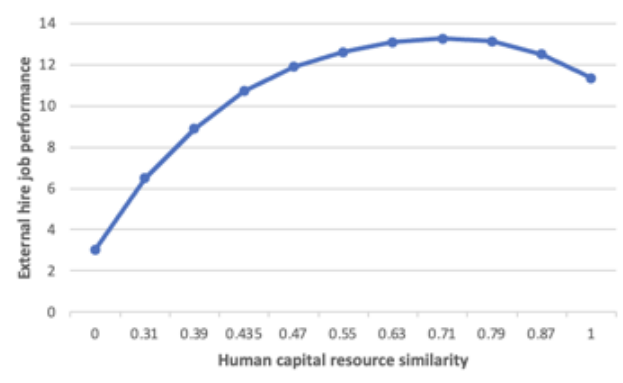

Figure 2: The inverted U-shaped relationship between human capital resource similarity and external hire performance

Figure 2 indicates that human capital resource similarity has an inverted U-shaped relationship with external hire job performance, which further supports Hypothesis. 


\section{Discussion}

\subsection{Theoretical Implications}

This study has examined how interdependence relationships between external hires and incumbents affect external hire job performance. Using a unique dataset collected from Chinese law firms, we found that human capital resource complementarity and similarity between external hires and incumbents have an inverted U-shaped relationship with external hire job performance. These findings suggest that interdependence, which consists of mutualism and competition, exists between external hires and incumbents and that it significantly affects external hire job performance. Though previous studies have argued that external hires and incumbents are interdependent $[5,11,36]$, we believe this study is one of the first to empirically examine how interdependence relationships between external hires and incumbents affect external hire job performance. The results of this study have several implications for the existing literature:

First, the previous studies have only examined the monotonic effects of interdependent relationship between external hires and incumbents on the outcomes of external hires. These prior studies either argue that interdependent relationship between external hires and incumbents helps firms by providing new working skills, abilities or needed knowledge, which in turn promotes external hire's performance or argue that it creates some losers as a result of the fact that external hires and incumbents compete for a set of limited resources[3,8,11]. Raffiee and Byun (2020) 's study is one of a few studies that empirically examine how interdependent relationship between external hires and incumbents affect external hires' outcomes although their focus (e.g., the moderating effect of interdependent relationship between external hires and incumbents on the relationship between mobility and external hire job performance) is different from our focus (e.g., how interdependent relationship between external hires and incumbents affects external job performance)[11]. However, Raffiee and Byun (2020)'s study has only examined the monotonic effects, in particular the positive effect of interdependent relationship between external hires and incumbents on external hire job performance[11]. In contrast, our study suggests that the effect of interdependent relationship between external hires and incumbents on external hire job performance is non-monotonic. In particular, we find that when human capital resource similarity and complementarity are at a low level, they both have a decreasingly positive effect on external job performance, which supports Raffiee and Byun (2020)'s argument that human capital resource similarity and complementarity are positively related to external hire job performance. But our study adds knowledge to the existing studies by suggesting that when human capital resource similarity and complementarity increase to a certain point, further increase in them will lead to an increasingly negative effect on external job performance. These empirical results support our argument that human capital resource similarity and complementarity have both mutualistic and competitive effects on external hires and that while both these two effects grow with the level of human capital resource similarity and complementarity, they grow at a different rate. In particular, mutualistic effect on external job performance grows with the level of human capital resource similarity and complementarity at a decreasing rate. In contrast, competitive effect on external job performance grows with the level of human capital resource similarity and complementarity at an increasing rate. Our inverted U-shaped effect of human capital resource similarity and complementarity on external hire job performance and consistent empirical results add new knowledge to the existing literature. We hope these findings will inspire future studies to further enquire into the effect of interdependent relationship between external hires and incumbents in other organizational contexts.

Second, this study adds the knowledge of external hire job performance. While the existing literature has emphasized the importance of interdependence between external hires and incumbents (or firms) [4,7,11,19], this study contributes to the existing literature by demonstrating how two dimensions of interdependence affect external hire job performance. Our empirical results demonstrate that external hires and incumbents are interdependent and that external hires are affected by their relations to incumbents. Ethiraj et al. (2005) have argued that external hires can become vibrant, which in turn raise their job performance, if their client-specific knowledge helps them establish a preferable relationship with incumbents[37]. Our study adds greater specificity to their insights by demonstrating that a preferable relationship between external hires and incumbents can occur through human capital resource similarity and complementarity. In particular, this study has shown that changes in human capital resource similarity and complementarity between external hires and incumbents alter external hires' job performance.

Third, this study has put mutualistic effect and competitive effect as a whole into consideration of how interdependent relationships between external hires and incumbents affect the outcomes of external hires. The existing literature addressing external hires' relations to incumbents has mainly focused on the benefits of human capital resource similarity and complementarity in the forms of resources flow, knowledge exchanges and ideas sharing[3,5,7,11,27]. But the possibility that the interdependent relationships between external hires and incumbents have both mutualistic effect and competitive effect on external hires has not been otherwise studied. To address this significant gap, this study has shown that interdependent relationships between external hires and incumbents have two different characters: competition and mutualism. Competition between external hires and incumbents is likely to occur when they compete for the same set scarce resources like promotion opportunities, clients, and employment opportunities. In other words, human capital resource similarity and complementarity between external hires and incumbents are likely to create competitions among them as a result of the fact that they tend to compete for the same set of resources. Meanwhile, external hires and incumbents with some degree of human capital resource similarity and complementarity are particularly prone to cooperate with each other due to the fact that a certain overlap in knowledge and skills can have an effect in disposing them to cooperate easily and efficiently. In this respect, we thus provide a more complete insight on how interdependence between external hires and incumbents affect the outcomes of external hires. 


\subsection{Practical Implications}

As has been emphasized in prior studies, the use of external labor markets has become ubiquitous[7,11]. However, the use of external hires cuts both ways, under favorable conditions, it helps firms stay abreast of changes in technologies, markets and society by providing new ideas and novel knowledge. But under unfavorable conditions, it hurts firms in that employers find it a challenge to integrate external hires into firms and to effectively utilize them in value creating activities[11]. Therefore, one of the most striking problems that firms in recent years are faced with is how they can effectively integrate and utilize external hires in firms' value-creating activities. This study provides insights for firms' managers, especially managers in human resources.

Our study suggests that managers need not only attend to external hires' own characters but to their human resource similarity and complementarity to firms. As Raffiee and Byun (2020) underscored, managers should be cognizant of the differences between human capital resource similarity versus complementarity[11]. This study adds knowledges by suggesting that managers ought to know the degree to which human capital resources of an external hire are similar to that of incumbents and to know the degree to which human capital resources of an external hire are complementary to that of incumbents. While we anticipated that interdependent relationship would have a striking effect on external hire job performance, the magnitude of the effect exceeded our anticipation. As the empirical results suggested in this article, all else being equal, an external hire's job performance would be 1.13 times larger if human capital resource complementarity were to change from 0 to 0.714 , and his job performance would drop as human capital resource complementarity further increases. All else being equal, an external hire's job performance would be 3.4 times larger if human capital resource similarity were to change from 0 to 0.811 , and his job performance would drop as human capital resource similarity further increases. These findings are especially important for managers to select suitable employees from external labor markets considering that most managers hardly recognize the importance of external hires' human capital resource similarity and complementarity. In this sense, this study helps firms understand the extent to which human capital resource similarity and complementarity can play a role to effectively integrate and utilize external hires in value creating activities.

\subsection{Limitations and Directions for Future Research}

This study has a few limitations which suggest some interesting avenues for future research.

First, this study is conducted within law firms, hence there remains a concern about its generalizability. It remains an open question whether our findings can be applied to other types of firms like technological firms, steel firms and auto firms. However, law firms, as Jia (2018) had put it, have quantities of characteristics with other business service contexts[38], which means our findings can be, at least, applied to service-based industries[39]. Future research which investigates interdependence between external hires and incumbents in non-service industries would be encouraged and valued.

Second, this study is not able to investigate a causal relationship between human capital resource similarity and complementarity and external hire job performance as a result of the fact that hiring from external labor market is an endogenous process[11]. Therefore, the extent to which human capital resource similarity and complementarity affect external hire job performance is not a random process. Simply because we have employed a Coarsened Exact Matching method in the regression estimation does mean we can claim a causal interpretation of our results. So, it would be an important and exciting direction for future research to investigate the causal relationship between human capital resource similarity and complementarity and external hire job performance by employing a longitudinal method that can be applied in examining the causal interpretation of our results.

Third, in this study, we are unable to investigate the contingent relationship between human capital resource similarity and complementarity and external hire job performance. For example, human resource management is a factor that may moderate the extent to which human capital resource similarity and complementarity affect external hire job performance. The logic that human capital resource similarity and complementarity can have a mutualistic effect on external hires works only if their managers can effectively organize and coordinate the contents of their work and only if they perceive they are fairly treated and are well respected by their supervisors and colleagues. Indeed, it is precisely this logic that persuades so many human resource managers to adjust their policies in order to effectively integrate and utilize external hires into value creating activities[27]. Human resource management practice is also a potent factor that may moderate the relationship between human capital resource similarity and complementarity and external hire job performance. A large quantity of studies has demonstrated that human resource management practice is like a catalyst that makes communications, learning and information sharing between employees much easier and more effective[1,27,40]. This underscores the need to keep investigating the relationship between human capital resource similarity and complementarity and external hire job performance. This study is one such attempt.

\section{References}

[1] T. Wang, C.D. Zatzick, "Human capital acquisition and organizational innovation: a temporal perspective,". Academy of Management Journal, 62(1), pp. 99-116, 2019.

[2] P. Cappelli, "Why we love to hate HR... And what HR can do about it,". Harvard Business Review, 93(7/8), pp. 54-61, 2015.

[3] G. Dokko, W. Jiang. The oxford handbook of talent management (chapter6: managing talent across organizations: the portability of individual performance), Oxford University Press, Oxford, U.K., 2017.

[4] B. Groysberg, L. Lee, et al, "What it takes to make 'star' hires pay off,". Mit Sloan Management Review, 21(2), pp. 57-61, 2010. 
[5] B.A. Campbell, B.M. Saxton, et al, "Resetting the shot clock: the effect of comobility on human capital,". Journal of Management, 40(2), pp. 531-556, 2014.

[6] G. Dokko, S.L. Wilk, et al, "Unpacking prior experience: how career history affects job performance,". Organization Science, 21(1), pp. 51-68, 2009.

[7] J. Raffiee, R. Coff, "Micro-foundations of firm-specific human capital: when do employees perceive their skills to be firm-specific?". Academy of Management Journal, 59(3), pp. 766-790, 2016.

[8] B.A. Campbell, R. Coff, et al, "Rethinking sustained competitive advantage from human capital,". Academy of Management Review, 37(3), pp. 376-395, 2012.

[9] A. Nyberg, G. Reilly, et al, "Human capital resources: a call to retire settled debates and to start a few new debates,". International Journal of Human Resource Management, 29(1), pp. 68-86, 2017.

[10] R.E. Ployhart, A.J. Nyberg, et al, "Human capital is dead; Long live human capital resources!". Journal of Management, 42(2), pp. 371-398, 2014.

[11] J. Raffiee, H. Byun, "Revisiting the portability of performance paradox: employee mobility and the utilization of human and social capital resources,". Academy of Management Journal, 63(1), pp. 34-63, 2020.

[12] H. Aldrich. Evolving, Sage Publications, Thousand Oaks, CA, 1999.

[13] W. Astley, "The two ecologies: population and community perspectives on organizational evolution,". Administrative Science Quarterly, 30(2), pp. 224-241, 1985.

[14] W. Barnett, G. Carroll, "Competition and mutualism among early telephone companies,". Administrative Science Quarterly, 32(3), pp. 400-421, 1987.

[15] J. Freeman, "Community ecology and the sociology of organizations,”. Annural Review of Sociology, 32(1), pp. 145-169, 2006.

[16] M. Hannan, J. Freeman. Organizational ecology., Harvard University Press, Cambridge, MA, 1989.

[17] Y. Zhang, H. Li, et al, "Intercommunity relationships and community growth in China's high technology industries 1988-2000,". Strategic Management Journal, 30pp. 163-183, 2009.

[18] M. Ruef, "The emergence of organizational forms: a community ecology approach,". American Journal of Sociology, 106(3), pp. 658-714, 2000.

[19] S.K. Ethiraj, P. Garg, "The division of gains from complementarities in human-capital-intensive activity,". Organization Science, 3pp. 725-742, 2012.

[20] P.M. Muchinsky, C.J. Monahan, "What is person-environment congruence? Supplementary versus complementary models of fit,". Journal of Vocational Behavior, 31(3), pp. 268-277, 1987.

[21] J.R. Edwards, "Person-environment fit in organizations: an assessment of theoretical progress,". Academy of Management Annals, 2(1), pp. 167-230, 2008.

[22] R.M. Hayes, P. Oyer, et al, "Coworker complementary and stability of top-management teams,". Journal of Law Economics and Organization, 22(1), pp. 184-212, 2006.

[23] D.M. Cable, J.R. Edwards, "Complementary and supplementary fit: a theoretical and empirical integration,". Journal of Applied Psychology, 89(5), pp. 822-834, 2004.
[24] P.S. Deortentiis, C.H. Van Iddekinge, et al, "Build or buy? The individual and unit-level performance of internally versus externally selected managers over time,". The Journal of Applied Psychology, 103(8), pp. 916-928, 2018

[25] B.E. Ashforth, F. Mael, "Social identity theory and the organization,". Academy of Management Review, 14(1), pp. 20-39, 1989.

[26] M. Bidwell, "Paying more to get less: the effects of external hiring versus internal mobility,". Administrative Science Quarterly, 56(3), pp. 369-407, 2011.

[27] I. Weller, C.B. Hymer, et al, "How matching creates value: cogs and wheels for human capital resources research,". Academy of Management Annals, 13(1), pp. 188-214, 2019.

[28] A.C. Cameron, J.B. Gelbach, et al, "Robust inference with multiway clustering,". Journal of Business \& Economic Statistics, 29(2), pp. 238-249, 2011.

[29] M. Bertrand, M. Bombardini, et al, "Is it whom you know or what you know? An empirical assessment of the lobbying process,". American Economic Review, 104(12), pp. 3885-3920, 2014.

[30] J.V. Blanes I, M. Draca, et al, "Revolving door lobbyists,". American Economic Review, 102(7), pp. 3731-3748, 2012.

[31] N. Bloom, M. Schankerman, et al, "Identifying technology spillovers and product market rivalry,". Econometrica, 81(4), pp. 1347-1393, 2013.

[32] S. Breschi, F. Lissoni, et al, "Knowledge-relatedness in firm technological diversification,". Research Policy, 32(1), pp. 69-87, 2003.

[33] A.B. Jaffe, "Technological opportunity and spillovers of R\&D: evidence from firms' patents, profits, and market values,". American Economic Review, 76(5), pp. 984-1001, 1986.

[34] G.S. Becker. Human capital: A theoretical and empirical analysis, with special reference to education, University of Chicago Press, Chicago, 1993.

[35] A. Eugenicos, "Should we reform the offences against the person act 1861?". Journal of Criminal Law, 81(1), pp. 26-32, 2017.

[36] M. Bidwell, J.R. Keller, "Within or without? How firms combine internal and external labor markets to fill jobs,". Academy of Management Journal, 57(4), pp. 1035-1055, 2014.

[37] S.K. Ethiraj, P. Kale, et al, "Where do capabilities come from and how do they matter? A study in the software service industry,". Strategic Management Journal, 26(1), pp. 25-45, 2005.

[38] N. Jia, "The "make and/or buy" decisions of corporate political lobbying: integrating the economic efficiency and legitimacy perspectives,". Academy of Management Review, 43(2), pp. 307-326, 2018.

[39] H. Byun, J. Raffiee, et al, "Discontinuities in the value of relational capital: the effects on employee entrepreneurship and mobility,". Organization Science, 30(6), pp. 1368-1393, 2019.

[40] A.S. Tsui, T.D. Egan, "Being different: relational demography and organizational attachment,". Administrative Science Quarterly, 37(4), pp. 549-579, 1992. 


\section{Author Profile}

Chen Ma is an assistant professor in Shangrao Normal University, School of Economics and Management. He received his PhD from Shanghai Jiao Tong University, Antai College of Economics and Management. And then he worked as a post-doctor at the University of Sydney Business School. His research focuses on Human capital resources, business ethics and corporate social responsibility.

Changjiang $\mathbf{Y u}$ is an assistant professor in Shangrao Normal University, School of Economics and Management. His current research focuses on abusive supervision, Human capital resources.

Junsheng Zhu holds the positions of University Distinguished Professor at Shanghai Jiao Tong University, Antai College of Economics and Management. Dr. Junsheng Zhu received his PhD in management from New York University in 1998. His current research focuses on Human capital resources, employee innovation activities. 